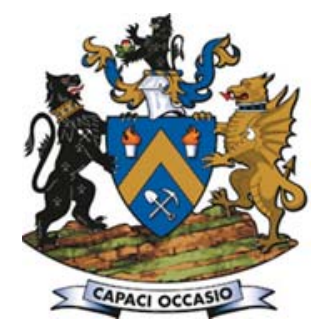

\title{
A survey of applications of multi- criteria decision analysis methods in mine planning and related case studies
}

\author{
by M.J. Mahase*, C. Musingwini*, and A.S. Nhleko*
}

\section{Synopsis}

In an environment like the mining industry, which is characterized by different stakeholders with multiple objectives, multi-criteria decision analysis (MCDA) is a useful approach for optimal decision-making. The application of MCDA techniques in the mining industry has predominantly been in mine planning and related problems, although no comprehensive survey has previously been undertaken to establish the application trends. A survey of the use of MCDA techniques was therefore conducted using case studies from the literature. It was noted that often two or more methods are applied to the same problem in order to increase confidence in the solution derived. As the number of criteria and alternatives increases, some methods become inefficient. A combination of the analytic hierarchy process (AHP) method with other MCDA techniques was the most frequently used approach, indicating the efficiency of the AHP method, especially when evaluating problems with more criteria and fewer alternatives. A combination of fuzzy theory with AHP or other methods incorporates uncertainty. The findings from the survey will benefit users applying MCDA techniques to solve mine planning and related problems..

Keywords

mine planning, multi-criteria decision-making (MCDM), multi-criteria decision analysis (MCDA), multi-objective decision-making (MODM), criteria, alternatives. other group of techniques within MCDM comprises the multi-objective decision-making (MODM) techniques. MODM techniques are generally used to solve problems with an infinite number of alternatives, while MCDA techniques are generally used to solve problems with a finite number of alternatives (Musingwini, 2010).

MCDA techniques have been frequently used to address decisions ranging from the strategic to the everyday (Petit and Fraser, 2013). The use of MCDA techniques has been extended to the mining industry, especially in mine planning and equipment selection (Musingwini, 2010). Mine planning and equipment selection are crucial in ensuring that a mine is run efficiently. For example, Sousa Junior et al. (2014) used the preference ranking organization method for enrichment evaluation (PROMETHEE) and elimination and choice expressing reality (ELECTRE) methods to select highway trucks for a mining operation. Musingwini and Minnitt (2008) ranked the efficiency of certain mining methods using the analytic hierarchy process (AHP). Yavuz (2015) selected equipment for a mine using Yager's method and AHP. Karadogan et al. (2008) used fuzzy set theory to select an underground mining method.

In this study, mine planning and related case studies are identified and categorized according to the MCDA methods used. The results are compared and a trend is established according to the number of criteria and alternatives. From the results, the appropriate method to use in specific case studies is determined, considering that each method has its own limitations, advantages, and disadvantages.
* School of Mining Engineering, University of the Witwatersrand, Johannesburg, South Africa.

(C) The Southern African Institute of Mining and Metallurgy, 2016. ISSN 2225-6253. Paper received Apr. 2016; revised paper received Jul. 2016. 


\section{A survey of applications of multi-criteria decision analysis methods in mine planning}

The investigation considered the most commonly used MCDA methods and how the methods were chosen for analysis. Case studies were identified and categorized according to the number of criteria and alternatives.

\section{Multi-criteria decision analysis techniques}

The mathematical frameworks of MCDA techniques do not form part of this paper as they are adequately explained elsewhere (e.g. Musingwini, 2010). Problem solving using MCDA techniques involves the following steps (Musingwini, 2010):

1. Identifying objectives and representing them as criteria

2. Assigning numerical values or weights to the criteria

3. Measuring the efficiencies of alternatives against different criteria to yield outcomes

4. Making an appropriate decision from the outcome.

To yield outcomes, an alternative $A_{i}$ is selected from a set of alternatives $A=\left\{A_{1}, A_{2}, \ldots \ldots ., A_{m}\right\}$. Alternative $A_{i}$ is measured against a decision criterion $C_{j}$ from a set of criteria $C=\left\{C_{1}, C_{2}, \ldots \ldots, C_{n}\right\}$. An outcome, $O_{i j}$ is determined by measuring the efficiency of $A_{i}$ against $C_{j}$. For $m$ alternatives and $n$ criteria, the alternatives and criteria are arranged in a $(m \times n)$ matrix to yield outcomes, as shown in Table I. From the outcomes, the alternative with the highest weighted outcome is taken as the ideal alternative except in the VIKOR method which uses the lowest weighted outcome, after reconfiguring the outcomes into dimensionless outcomes as the weighted outcome is derived as an additive function.

Many MCDA methods have been established and their use extended to the mining industry. Various authors have used different sources to identify the most commonly used MCDA methods. Velasquez and Hester (2013) used databases like Springer, ScienceDirect, IEEExplore, journal articles, and conference proceedings to identify publications on MCDA. The identified publications were narrowed to those dealing with the most commonly used methods.

Eleven methods, namely multi-attribute utility theory (MAUT); analytic hierarchy process (AHP); fuzzy set theory; case based reasoning (CBR); data development analysis (DEA); simple multi-attribute rating technique (SMART); goal programming; elimination and choice expressing reality (ELECTRE); preference ranking organization method for

\section{Table I}

The structure of a generic multi-criteria decision analysis problem (Musingwini, 2010)

\begin{tabular}{|c|c|c|c|c|c|c|c|}
\hline \multicolumn{2}{|c|}{} & \multicolumn{7}{|c|}{ Criteria } \\
\cline { 2 - 7 } \multicolumn{2}{|c|}{} & $C_{1}$ & $C_{2}$ & $\cdots$ & $C_{j}$ & $\cdots$ & $C_{n}$ \\
\hline Alternatives & $A_{1}$ & $O_{11}$ & & & & & \\
& $A_{2}$ & & $O_{22}$ & & & & \\
& $\ldots$ & & & $\cdots$ & & & \\
& $A_{i}$ & & & & $O_{i j}$ & & \\
& $\ldots$ & & & & & $\cdots$ & $O_{i j}$ \\
\hline
\end{tabular}

$A$ : Alternatives, where a set of alternatives $A=\left(A_{1}, A_{2}, \ldots \ldots, A_{m}\right)$ $C$ : Criteria, where a set of criteria $C=\left(C_{1}, C_{2}, \ldots \ldots, C_{n}\right)$ $O$ : Outcomes, they measure the efficiency alternative $A_{i}$ against criterion $C_{j}$, to get outcome $O_{i j}$ enrichment evaluation (PROMETHEE); simple additive weighing (SAW); and technique for order preference by similarity to ideal solution (TOPSIS) methods were identified. MAUT was the most commonly used method in conjunction with other methods when two or more methods were used. The use of two or more methods provides an alternative method to make up for the shortcomings any one of the particular methods (Velasquez and Hester, 2013).

Fulop (n.d.) classified multi-attribute decision-making methods into cost-benefit analysis (CBA), elementary methods, MAUT methods, outranking methods, group decision-making methods, and sensitivity analysis. Elementary methods were subdivided according to pros and cons analysis, minimum and maximum methods, conjunctive and disjunctive methods, and lexicographic methods. The MAUT methods were classified into SMART, generalized means, and AHP; and outranking methods into PROMETHEE and ELECTRE methods.

Figueira, et al. (2005) classified outranking-based multiple criteria decision methods which were based on pairwise comparison of actions into outranking methods, multi-attribute utility and value theories (MAUT/ MAVT), and non-classical MCDA approaches. The outranking methods were further divided into ELECTRE methods, PROMETHEE methods, pairwise criterion comparison approach, and one outranking method for stochastic data. MAUT/ MAVT were divided into MAUT method, utilities additives (UTA) method, analytic network process (ANP), AHP, and measuring attractiveness by a categorical-based evaluation technique (MACBETH). Non-classical MCDA approaches were introduced to account for any uncertainties associated with a changing environment. Under non-classical MCDA approaches the fuzzy set approach and technique for ordinal multi-attribute sorting and ordering (TOMASO) toolbased software were considered.

Sanandaji (2006) referred to decision-making methods as models and classified them into MCDM, MADM, rational decision-making, irrational decision-making, and nonrational decision-making models. MCDM was further divided into ELECTRE-II, PROMETHEE-II, AHP, compromise programming (CP), and multi-criterion $Q$-analysis (MCQA). MADM was subdivided into SAW, weighted product (WP) method, and TOPSIS.

Peniwati (2007) identified 15 MCDA methods and divided them into structuring methods, ordering and ranking methods, and structuring and measuring methods. Analogy association, boundary examination, brainstorming or brain writing, morphological connection, and why-what's-stopping methods were categorized under structural problems. Structuring and measuring methods consisted of Bayesian analysis, MAUT, and AHP. Ordering and ranking methods included voting method, nominal group technique, Delphi technique, disjointed incrementalism, matrix evaluation, goal programming, conjoint analysis, and outranking methods.

De Montis, et al. (2008) identified the most commonly used methods to address problems involving sustainable development and stakeholder involvement. The seven MCDA methods identified were assessed in terms of their usefulness and application. The methods were then classified into single criterion approach methods, outranking methods, and programming methods. Single criterion approach methods 


\section{A survey of applications of multi-criteria decision analysis methods in mine planning}

were classified into CBA, MAUT, AHP, and evaluation matrix (Evamix). ELECTRE III, regime, and novel approach to imprecise assessment, and decision environments (NAIADE) were classified under outranking methods. Programming methods were divided into goal programming and multiple objective programming.

Musingwini (2010) identified five most commonly used MCDA techniques based on their frequency of use in the mining industry as well as in other sectors. The identified techniques were MAUT, AHP, ELECTRE, PROMETHEE, and TOPSIS. The identified techniques were then compared under criteria of foundation, theoretical basis, measurement criteria, and determination of weights of criteria to show the unique properties of each technique.

\section{Methodology}

Case studies solved using MCDA techniques were identified from different journal sources and conference proceedings. The identified case studies were narrowed down to those dealing with mine planning and related studies. A total of 150 case studies solved using multi-criteria methods were identified and grouped according to the method of analysis applied (Table II). Where a case study was published in more than one journal, it was accounted for only once in order to eliminate bias.

After grouping the case studies based on the methods used to solve them, the frequency of use technique was applied as an indicator to determine the most used method. The method selected using this technique may not necessarily be the best, although it may be frequently used owing to its simplicity.

\section{Results and analysis}

The most frequently used manner of solving multi-criteria problems is a combination of two or more techniques, followed by the use of AHP and then fuzzy set theory. The usage of two or more methods compensates for the shortcomings of the alternative methods when solving a particular problem (Velasquez and Hester, 2013).

Due to its simplicity, AHP is the second most used methodology after the combination of MCDA techniques (Velasques and Hester, 2013). AHP is also less dataintensive than MAUT. AHP is compared to MAUT because

\begin{tabular}{|l|c|}
\hline \multicolumn{2}{|l|}{ Table II } \\
MCDA methods used to solve the identified case \\
\multicolumn{2}{|l|}{ studies } \\
\hline Method & Frequency \\
\hline Combination of methods & 81 \\
AHP & 45 \\
Fuzzy set theory & 8 \\
PROMETHEE & 4 \\
TOPSS & 3 \\
MAUT & 2 \\
Yager's method & 2 \\
VIKOR method & 2 \\
ELECTRE & 1 \\
Folchi algorithm & 1 \\
Integrated grey cluster and entropy-weight method & 1 \\
\hline Total & 150 \\
\hline
\end{tabular}

both methods use pairwise comparison of criteria (Alexander, 2012). On the other hand, the interdependence between criteria has made AHP unfavourable (Velasquez and Hester, 2013). Judgement and ranking of criteria can be inconsistent during the pairwise comparison of criteria. This implies that although AHP is frequently used due to its simplicity, other techniques can be used concurrently with AHP to address its shortcomings.

The combination of different MCDA techniques and AHP is discussed in detail due to its high frequency of usage in mine planning and related case studies. AHP is the most frequently used technique to address mine planning problems, which include the selection of an optimum mining method, evaluation of transportation methods, selection of optimal mining equipment, and suitable land use alternatives for mined land. AHP links criteria at upper levels to criteria at lower levels, through division of the criteria into sub-criteria. AHP is considered to efficiently rank criteria because of the pairwise comparison of criteria. However, AHP requires a high level of knowledge and experience from the decisionmaker. AHP does not incorporate risk and uncertainties (Shahroodi et al., 2012).

The mining environment is characterized by uncertainty (Saaty, 2007) so it is necessary to incorporate uncertainty in decision-making. Figure 1 shows the different criteria and alternatives for the case studies solved using AHP. Most case studies consider a maximum of 20 criteria and 9 alternatives (Figure 2). With increasing numbers of criteria and

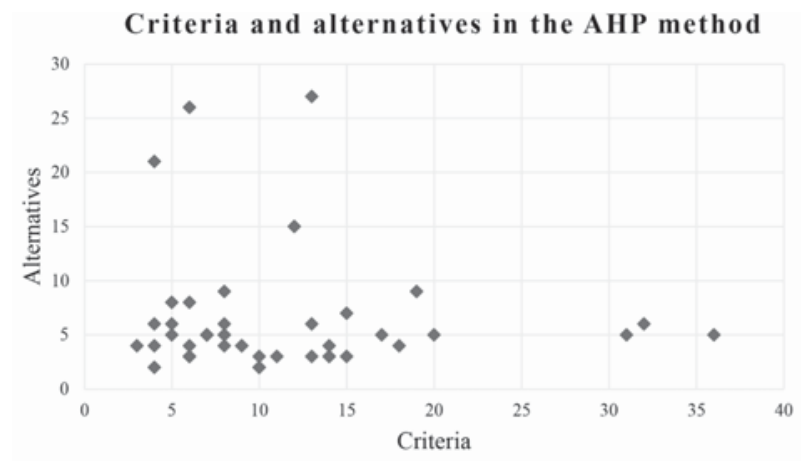

Figure 1-Criteria and alternatives for cases solved by the AHP technique

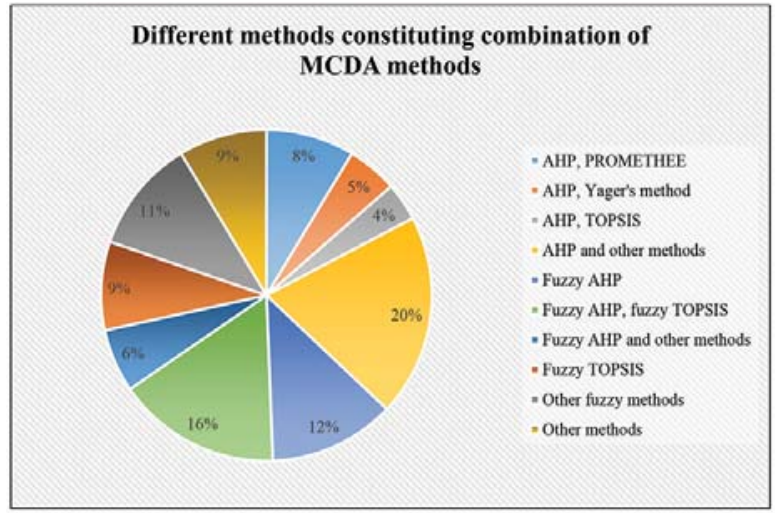

Figure 2-Different methods constituting combinations of MCDA methods 


\section{A survey of applications of multi-criteria decision analysis methods in mine planning}

alternatives, it may not be feasible to use the AHP method due to the uncertainty associated with a large number of alternatives and criteria. According to Yavuz and Altay (2015), the recommended maximum number of criteria to be handled by AHP is 9, due to the limitations of human abstract thinking. In cases where the number of criteria is greater than 9, criteria should be decomposed into subcriteria, such that the main criteria do not exceed 9, but each criterion has several sub-criteria.

\section{Combination of different MCDA techniques}

A combination of different techniques is used to make up for the shortcomings of any one technique (Velasquez and Hester, 2013). It increases the level of precision since it allows for a comparison of solutions from different techniques. Table II indicates that 81 of the 150 case studies were solved using a combination of methods. Table III presents the various combinations of the MCDA techniques. AHP in combination with other methods was the most frequently used, followed by the combination of fuzzy MCDA methods. The combination of AHP with PROMETHEE was followed by fuzzy TOPSIS in conjunction with other methods. The combination of fuzzy AHP and other methods was the least frequently used. A graphical presentation of the frequency of different combinations of MCDA methods is shown in Figure 2. Table III and Figure 2 show that AHP is the most commonly used MCDA method in combination with other methods in mine planning, with a $20 \%$ frequency.

Figure 2 illustrates the different combinations of MCDA methods used to solve the case studies. Most case studies are solved using a combination of AHP and other MCDA techniques. For instance, a combination of AHP with fuzzy set theory, PROMETHEE, or TOPSIS are present, making AHP a frequently combined method. AHP can be used to solve strategic and long-term mine planning problems.

Figure 3 presents the criteria and alternatives of MCDA method combinations with AHP used to address different case studies. The number of criteria has increased up to 25 , and in one case as many as 50 criteria are seen. The number of criteria increased in comparison to when AHP was the only method used for analysis, as shown in Figure 1. More criteria in a decision means more precision is required. The number of alternatives has also decreased to a maximum of 20 compared to 28 where AHP was the only method used. As

Table III

\section{Combination of MCDA methods used to solve identified case studies}

\begin{tabular}{|l|c|}
\hline Method combination & Frequency \\
\hline AHP and other methods & 16 \\
Fuzzy AHP, fuzzy TOPSIS & 13 \\
Fuzzy AHP & 10 \\
Other fuzzy methods & 9 \\
AHP, PROMETHEE & 7 \\
Fuzzy TOPSIS & 7 \\
Other methods & 7 \\
Fuzzy AHP and other methods & 5 \\
AHP, Yager's method & 4 \\
AHP, TOPSIS & 3 \\
Total & 81 \\
\hline
\end{tabular}

the number of criteria increases, the possible alternatives are narrowed down. Applying a combination of different methods yields a more accurate result than using a single MCDA method for analysis.

There are uncertainties associated with decision-making, which are due to the subjective judgement of the decisionmaker or incomplete data (Yazdani-Chamzini and Yakhchali, 2012). Mine planning problems are often associated with incomplete data. For example, geostatistics is used to solve the problem of incomplete data as modelling has to be done on geological data from drilling. To address uncertainty, fuzzy theory is combined with different MCDA techniques (Yazdani-Chamzini and Yakhchali, 2012). Fuzzy MCDA methods are the most frequently used methods, accounting for $54 \%$ of the total combination of methods. Figure 4 shows that the range of criteria increased relative to the non-fuzzy AHP method. Using fuzzy theory results in an increased number of criteria and a decrease in number of alternatives. This observation is expected because as more constraints are considered, the more specific the problem becomes. As a result, irrelevant options are eliminated.

Figure 5 summarizes the observations in Figures 1, 3, and 4 . It can be concluded that as the number of criteria increases, the number of alternatives decreases. This imparts a level of confidence to decision-making, since all the redundant alternatives are omitted. Preliminary findings based on the analysis of case studies using more than one MCDM method indicate that stable results are obtained when a maximum of four alternatives and six criteria are evaluated.

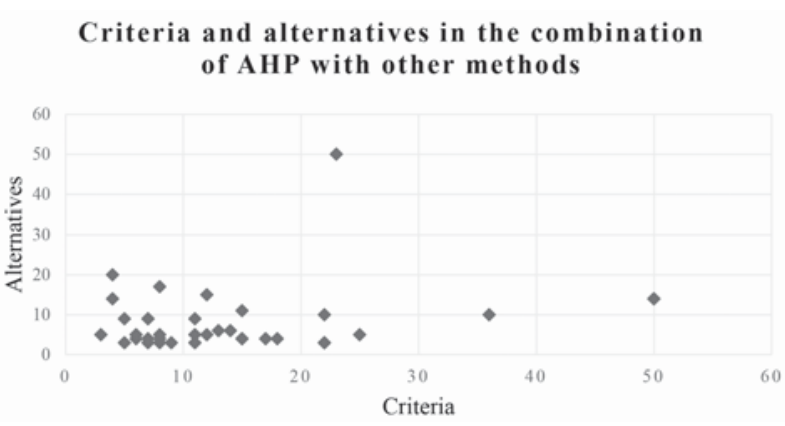

Figure 3-Criteria and alternatives in the combination of AHP with othe MCDA methods

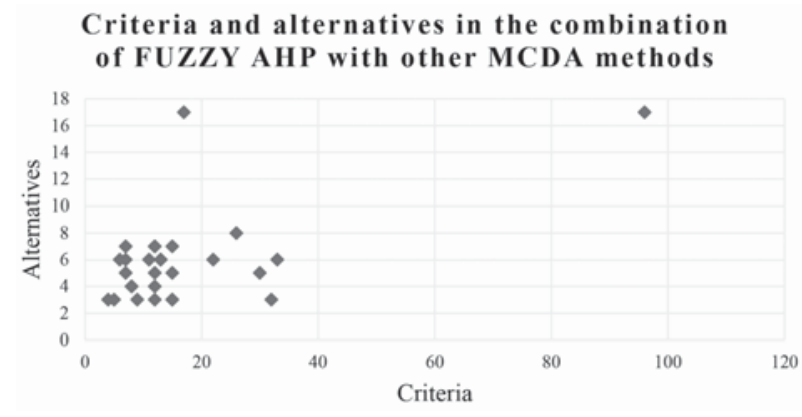

Figure 4-Criteria and alternatives in the combination of fuzzy AHP with other methods 


\section{A survey of applications of multi-criteria decision analysis methods in mine planning}

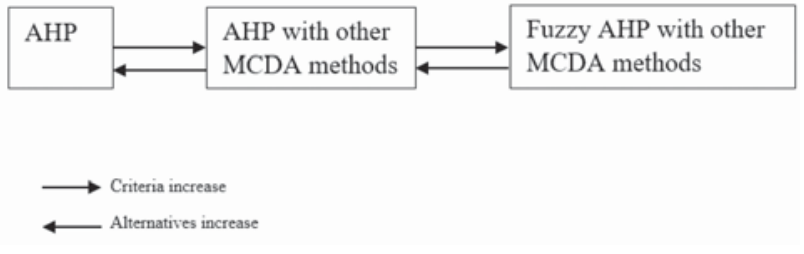

Figure 5-Impact of different combinations of MCDA methods on criteria and alternatives

\section{Conclusions}

In the mining industry, different stakeholders have different objectives that have to be met, and these translate into criteria. MCDM techniques are used to obtain an optimal solution to satisfy key stakeholders criteria. MCDA techniques are the branch of MCDM techniques that is used to address mine planning problems that have multiple, but finite criteria and several alternatives. A total of 150 mine planning and related case studies that have been solved using multi-criteria methods were identified and grouped according to the method of analysis in each case study. Each MCDA technique has strengths and weaknesses. In order to address the shortcomings of any one method, a combination of two or more different methods can be used. The most commonly used combination was AHP with other methods. Fuzzy theory was used in cases where uncertainty had to be considered.

It was noted that often one, two, or three methods are applied to the same problem in order to attach confidence to the optimal decision. As the number of criteria and alternatives increases, some of methods become inefficient. The combination of the analytic hierarchy process (AHP) method with other MCDA techniques was the most frequently used approach, indicating the efficiency of the AHP method, especially when more criteria and fewer alternatives are evaluated. Fuzzy theory was combined with AHP or other methods to incorporate uncertainty. It is envisaged that this study will be extended by applying the selected MCDA methods to each of the selected case studies to establish trends in the efficiency of each method as the number of criteria and alternatives increases. This will provide further insight to users of MCDA techniques when solving mine planning and related problems.

When more criteria are used, the number of alternatives should be reduced through a pre-screening process in order to reduce inconsistencies that may occur. Similarly, when there are several criteria, these should be consolidated into main or primary criteria in order reduce the number of criteria used for the ranking of alternatives. The most unlikely alternatives are thus eliminated, thus reducing the likelihood of choosing an incorrect alternative. Preliminary findings for the case studies analysed indicate that a combination of a maximum of four alternatives and six criteria tends to produce stable results.

\section{Acknowledgement}

This study forms part of an MSc research project undertaken at the University of the Witwatersrand.

\section{References}

ALEXANDER, M. 2012. Decision-making using the analytical hierarchy process, IMP Summit, 2012. pp. 1-15. http://www.do-cu-cu.com/view/ aecd0b5a85af7cefa4cfa3a207focf01/Decision-Making-Using-theAnalytic-Hierarchy.pdf [Accessed 2 April 2016].

De Montis, A., Toro, P.D., Droste-Franke, B., and Ines Omann, S.S. 2014. Assessing the quality of different MCDA methods. http://people.unica.it/ adm/files/2008/11/05_de_monti_et_al.pdf [Accessed 21 January 2016].

Figueira, J., Greco, S., and EhrgotT, M. 2005. Multiple Criteria Decision Analysis: State of the Art Surveys. Kluwer Academic Publishers, London. http://www.springer.com/it/book/9780387230672 [Accessed 18 January 2016].

FuLoP, J. Not dated. Introduction to Decision-making Methods. Hungarian Academy of Sciences. pp. 1-15. http://academic.evergreen.edu/projects/ bdei/documents/decisionmakingmethods.pdf [Accessed 18 January 2016].

Herath, G. and Prato, T. 2006. Role of multi-criteria decision making in natural resource management. Using Multi-criteria Decision Analysis in Natural Resource Management. Herath, G. and Prato, T. (eds.). Ashgate, Hampshire, UK. pp. 1-8. https://books.google.co.za/books?id=xlyc VeiUJ2UC\&pg=PA1\&lpg=PA1\&dq=Using+multi-criteria+decision + in + a + natural+resource+management+Herath+and+Prato\&source=bl\&ots=ReJW D9LYGu\&sig=lv7m3gzVrW4PRIiREIsWBMuyTDU\&hl=en\&sa=X\&ved=0ah UKEwi2rrGn-8nLAhXIvRoKHdgNAQUQ6AEIIDAB\#v=onepage $\& \mathrm{q}=$ Using\%20multi-criteria\%20decision\%20in\%20a\%20natural\%20resource $\% 20$ management $\% 20$ Herath\%20and\%20Prato\&f=false [Accessed 20 February 2016].

Karadogan, A., Karhiman, A., and Ozer, U. 2008. Application of fuzzy set theory in the selection of an underground mining method. Journal of the Southern African Institute of Mining and Metallurgy, vol. 108, no. 2. pp. 73-79. http://www.scielo.org.za/pdf/jsaimm/v108n2/02.pdf [Accessed 1 March 2016].

MusingwinI, C. and MinnitT, R.A. 2008. Ranking the efficiency of selected platinum mining methods using the analytical hierarchy process. Proceedings of the Third International Platinum Conference: 'Platinum in Transformation, Sun City, South Africa, 5-9 October 2008. Southern African Institute of Mining and Metallurgy, Johannesburg. pp. 319-326. http://www.hydrometallurgy.co.za/Pt2008/Papers/319326_Musingwini.pdf [Accessed 20 February 2016].

MusingwinI, C. 2010. A review of the theory and application of multi-criteria decision analysis techniques in mine planning. Proceedings of Mine Planning and Equipment Selection (MPES) 2010, Australasian Institute of Mining and Metallurgy, Melbourne. pp. 129-140.

Peniwati, K. 2007. Criteria for evaluating group decision making methods. Mathematical and Computer Modelling, vol. 46, no. 7-8. pp. 935-947. http://www.sciencedirect.com/science/article/pii/S0895717707001021 [Accessed 2 March 2016].

PetrT, P. and Fraser, P. 2013. What is the best energy-delivery system for hand-held stope drilling and associated equipment in narrow-reef hard rock mines? Journal of the Southern African Institute of Mining and Metallurgy, vol. 113, no. 3. pp. 243-249. http://www.scielo.org.za/pdf/ jsaimm/v113n3/14.pdf [Accessed 20 January 2016].

SAATY, T. 2007. Multi-decisions decision-making: in addition to wheeling and dealing our natural political bodies need a formal approach to prioritization. Mathematical and Computer Modelling, vol. 46, no. 7. 


\section{A survey of applications of multi-criteria decision analysis methods in mine planning}

pp. 1001-1006. http://www.sciencedirect.com/science/article /pii/S0895717707000817 [Accessed 23 February 2016].

SANANDAJI, H. 2006. A study of different decision-making models and their pros and cons. Carleton University, Ottawa, ON, Canada. pp. 1-14.

Shahroodi, K., KeramatPanah, A., Amini, S., and Haghighi, K.S. 2012. Application of analytical hierarchy process technique to evaluate and selecting suppliers in an effective way. Kuwait Chapter of Arabian Journal of Business Management Review, vol. 1, no. 8.

http://www.arabianjbmr.com/pdfs/KD_VOL_1_8/1.pdf [Accessed 1 April 2016].

Sousa, T.W. JR, SouZA, M.J.F., CABRAL, I.E., and Diniz, M.E. 2014. Multi-criteria decision aid methodology applied to highway truck selection at a mining company. Revista Escola de Minas, Ouro Preto, vol. 67, no. 3. pp. 285-290. http://www.scielo.br/pdf/rem/v67n3/a07v67n3.pdf [Accessed 20 February 2016].

Velasquez, M. And Hester, P.T. 2013. An analysis of multi-criteria decision making methods. International Journal of Operations Research, vol. 10, no. 2. pp. 56-66. http://www.orstw.org.tw/ijor/vol10no2/ ijor_vol10_no2_p56_p66.pdf [Accessed 12 February 2016].
YAvUZ, M. 2015. Equipment selection based on the AHP and Yager's method. Journal of the Southern African Institute of Mining and Metallurgy, vol. 115, no 5. pp. 425-433. http://www.scielo.org.za/pdf/jsaimm/ v115n5/15.pdf [Accessed 19 February 2016]

YavuZ, M. and Altay, B.L. 2015. Reclamation project selection using fuzzy decision making methods. Environmental Earth Sciences, vol. 73, no. 10. pp. 6167-6179. http://download.springer.com/static/pdf/166/art\% 253A10.1007\%252Fs12665-014-3842-0.pdf?originUrl=http\%3A\% 2F\%2Flink.springer.com\%2Farticle\%2F10.1007\%2Fs12665-014-3842O\&token2=exp=1459771329 acl=\%2Fstatic\%2Fpdf\%2F166\%2Fart\%2525 3A10.1007\%25252Fs12665-014-3842-0.pdf\%3ForiginUrl\%3Dhttp\% 253A\%252F\%252Flink.springer.com\%252Farticle\%252F10.1007\%252Fs 12665-014-3842-0* $\sim$ hmac=80a8a1a83a86778109a171e812da53 b1e7e820453abd2eb5bbd36169348a7050 [Accessed 31 March 2016].

YAZDANI-CHAMZINI, A. and YAKHCHALI, S.H. 2012. Handling equipment selection in open pit mines based on group decision making. Journal of Industrial Engineering Computations, vol. 3, no. 105. pp. 907-924. http://www.growingscience.com/ijiec/Vol3/IJIEC_2012_42.pdf [Accessed 30 March 2016]. 